\title{
SURVEY OF PUBLIC ATTITUDE TOWARDS BOTTLED AND TAP WATER QUALITY IN THE UAE
}

\author{
MARAQA M.A. ${ }^{1, *}$ \\ GHOUDI K. ${ }^{2}$
}

\author{
${ }^{1}$ Department of Civil and Environmental Engineering, UAE University
}

${ }^{2}$ Department of Statistics, UAE University

Received: $24 / 04 / 2015$

Accepted: 20/07/2015

Available online: $27 / 08 / 2015$

*to whom all correspondence should be addressed:

\section{ABSTRACT}

The United Arab Emirates (UAE) is one of the leading countries in the per capita bottled water consumption. This seems to be in controversy with adherences of local water authorities to stringent municipal water standards. A public survey $(n=891)$ was conducted to ascertain the perception of people in the country regarding bottled and tap water quality. The survey form was formulated based on the stated preference approach and was furnished in both Arabic and English languages. Some questions in the survey form require rating the quality of tap water and identifying the type of water the respondent drinks. For respondents who usually drink bottled water, they were asked to choose the reason(s) why they usually drink bottled water. Those who drink tap water more often were similarly asked to choose the reason(s) why they prefer tap water to bottled water. The study revealed that a large fraction of the UAE residents classify the quality of tap water as either good or excellent, yet many of them drink bottled water. This could be attributed in part to the high standard of living where the cost of bottled water is considered by the majority of the respondents as affordable. Other influential factors include the belief that bottled water has a better taste and concerns about tap water contamination. The latter may stem from the perception that water is not sufficiently treated or contamination is induced into the water from the distribution system or the in-house storage tanks. The study shows that more people in the UAE will drink tap water if relevant authorities provide information about tap water quality and if regular inspections and cleaning of the in-house storage tanks is conducted.

Keywords: Bottled water, tap water, quality perception, public survey

\section{Introduction}

In spite of the availability of cheap good quality tap water in many countries, bottled water consumption tremendously increased in the last 4 decades at an annual worldwide growth rate of 7\% (Ferrier, 2001). As a result, bottled water has become the fastest growing segment of non-alcoholic beverages, representing a market worth $\$ 22$ billion (Ferrier, 2001). In arid regions where nonconventional water resources are utilized and weather conditions require the consumption of more water, increases in bottled water consumption were more noticeable. For example, doubling bottled water consumption was reported in the Middle East between 2003 and 2008 (Saleem, 2008).

The main two reasons that cause public dissatisfaction with tap water are organoleptics (i.e. taste, odor, color and turbidity) and health/risk concerns (Doria, 2006; 2010). In some surveys, however, bottled water seems to be mostly consumed as a substitute for other beverages (FWR, 1996). People also drink bottled water

Maraqa M.A. and Ghoudi K. (2015), Survey of public attitude towards bottled and tap water quality in the UAE, Global NEST Journal, 17(3), 607-617. 
thinking it has additional benefits for their health, but not necessarily because of tap water risks (Finucane $e t$ al., 2000; Black, 2009). However, there is evidence that bottled water in some developed (Olson, 1999; Cidu et al., 2011) and developing (Nsanze et al., 1999; Dabeka et al., 2002; Mahajan et al., 2006) countries is not as healthy as sometimes proclaimed. As stated by Doria (2006), bottled water is not necessarily better than tap water but that depends on the specificity of the considered case. Therefore, it seems paradoxical that people choose to drink bottled water given that this option is much more expensive (Olson, 1999), less comfortable, and has more negative environmental impact (Freire et al., 2001; Botto et al., 2011) than tap water.

Factors that affect public perception of water quality are diverse. Concerns regarding tap water quality could be attributed to demographic variations including race, age, income, occupation and gender (FWR, 1996; Abrahams et al., 2000; Dupont et al., 2010). Also, the perceived quality of the water source can be a significant predictor of bottled water consumption (Levallois et al., 1999; Anadu and Harding, 2000; Pintar et al., 2009; Hu et al., 2011). Other factors that influence public behavior are past incidents of tap water contamination, trust in tap water companies, marketing of bottled water companies (Giacosa and Giovando, 2012), changes of life style, increasing standards of living, the wide spread markets of bottled water (Ferrier, 2001), among others.

In the last five years, the United Arab Emirates (UAE) was among the top 6 countries worldwide in the annual per capita bottled water consumption of about 40 gallons compared to a global average of 8.8 gallons (IBWA, $2009 ; 2010 ; 2011 ; 2012 ; 2013)$. This increase in per capita bottled water consumption appears to contradict the adherence of local water authorities to stringent municipal water standards. Our objective was to ascertain the perception of people in the country regarding bottled and tap water quality. Such knowledge can assist in understanding public concerns and behaviors associated with drinking bottled and tap water.

\section{Methodology}

The UAE consists of 7 emirates: Abu Dhabi, Dubai, Sharjah, Ajman, Fujairah, Ras Al Khaima, and Umm Al Qaiwain. The country is characterized by a tropical dry weather, with relatively high temperatures throughout the year, especially in summer. The estimated population of the UAE in 2013 is about 6.3 million, with almost $40 \%$ of the population is located in the Emirate of Abu Dhabi (UAE Year Book, 2013). Meanwhile, a large fraction of the residents (75\%) are expatriates (Maraqa and Mohamed, 2013). The country is considered one of the richest in the world with a gross domestic product (GDP) of US $\$ 375$ billion. Abu Dhabi Emirate contributes approximately $60 \%$ of the GDP, followed by Dubai at $30 \%$, Sharjah at $5 \%$, and the remaining $5 \%$ are distributed among the other emirates (UAE Year Book, 2013).

In order to assess public perception towards bottled and tap water quality, a preliminary survey form was prepared and distributed to a limited number of UAE residents to assure the questions are understandable, not long-winded, and free of technical jargons. Based on this, the survey from was modified and was then distributed to a statistically sufficient number of residents. A copy of the survey form is shown in Appendix A. Forms were collected during the period of 2011-2014. The sample size was calculated from Eq. (1), which gives the minimum number of survey forms that are required for a given confidence level with a normal distribution response of a large population size (Roses et al., 2004).

$$
N=\frac{z^{2} s^{2}}{e^{2}}
$$

where, $N$ is the minimum sample size; $z$ is the $z$-value of a given confidence level (for $95 \%$ confidence level it is 1.96); $s$ is the coefficient of variation (assumed as 0.5 ) and $e$ is the tolerance level (assumed as 5\%). Based on Eq. (1), the minimum sample size was found to be 384. A total of 891 filled survey forms were collected from all the different emirates which far exceeds the minimum number required to be collected. Form 
distribution was carried out using a paper-administered method. The survey targeted residents who are 18 years or older. The respondents were either nationals of the UAE or expatriates who are residing in the country for at least 2 years. The latter constraints excluded many short-term visitors or temporary workers who reside in the country for less than 2 years.

Some of the questions in the survey form were intended to identify the respondent's nationality, age, education, etc. Respondents were asked to rate the quality of tap water at their residence and to indicate the type of water they drink (i.e. bottled, tap, or both). They were also asked about the frequency they drink tap water. For those who usually drink bottled water, they were asked to choose from a given list the reason(s) why they usually drink bottled water most often. Similarly, those who drink tap water more often were asked to choose the reason(s) why they usually drink tap water most often. Respondents were also asked to choose the concerns they have about drinking tap or bottled water. They were also asked about the cost of bottled water. Respondents were further asked if they have a ground tap water storage tank and the frequency the tank is cleaned. They were also asked if they have a roof water storage tank and how often it is cleaned. In another question, respondents were asked to choose among a given list the action(s) that could be done to encourage them to drink more tap water. Finally, respondents were asked about the source from which they obtain information about tap and bottled water quality.

The survey form was formulated based on the stated preference approach. In some of the survey questions, respondents were asked to choose one answer from a given list. In other questions, respondents were requested to choose all applicable answers from a given list (see for example questions 11-14 and 27-29). In the analysis of the latter set of questions; the answers are expressed in terms of percent responses relative to the total number of responses received. The survey form was furnished in both Arabic and English languages. A platform was developed to ease the entry of data into a spread sheet. Survey results were analyzed using summaries of descriptive statistics. Meanwhile, cross tabulation using Pearson Chi-Square analysis was conducted to investigate possible association between responses received on different issues asked in the questionnaire.

\section{Results}

Figure 1 shows some demographical characteristics of the respondents. About $55 \%$ of the respondents are from Abu Dhabi Emirate, 12\% from Sharjah, 11\% from Ras Al Khaima, and the remaining (22\%) are from the other four emirates. Almost two-thirds of the respondents are 18 to 25 years old and the second largest group (17.1\%) are 26 to 35 years old. Most of the respondents are UAE nationals (77.9\%), while the second largest group are Arab residents (14.8\%). Also, about $71 \%$ of respondents have a university degree, and $26.3 \%$ completed secondary school.

More than $68 \%$ of the respondents classified tap water as either good or excellent (Fig. 2). However, $78 \%$ of the respondents prefer drinking bottled water, with $88 \%$ of them indicated that they rarely or never drank tap water. According to the respondents, the cost of bottled water in the UAE is reasonable (60\%) or cheap (32\%). Meanwhile, half of the respondents select bottled water based on quality, $37 \%$ based on availability, and $9.5 \%$ based on cost. Our findings are consistent with those reported in previous studies which indicated that bottled water in the UAE is consumed by 77\% (Wait, 2008) to 90\% (Mahajan et al., 2006) of the population. However, our findings differ from those of Wait (2008), who found that only $26.4 \%$ of the UAE respondents rate their tap water as good or excellent. Variations in this regard possibly reflect an improved public perception of the quality of tap over time.

While all surveyed age groups prefer drinking bottled water, those who are 18 to 25 years old constitute the highest percentage (77.6\% relative to the group). Meanwhile, all nationalities prefer drinking bottled water but UAE nationals constitute the highest percentage ( $78.3 \%$ relative to the group). Also, residents of all seven emirates prefer drinking bottled water but those who reside in Abu Dhabi constitute the highest percentage 
(76.2\% relative to the group). Furthermore, those who selected reasonable cost for bottled water price constitute $76.6 \%$ among those who prefer to drink bottled water.
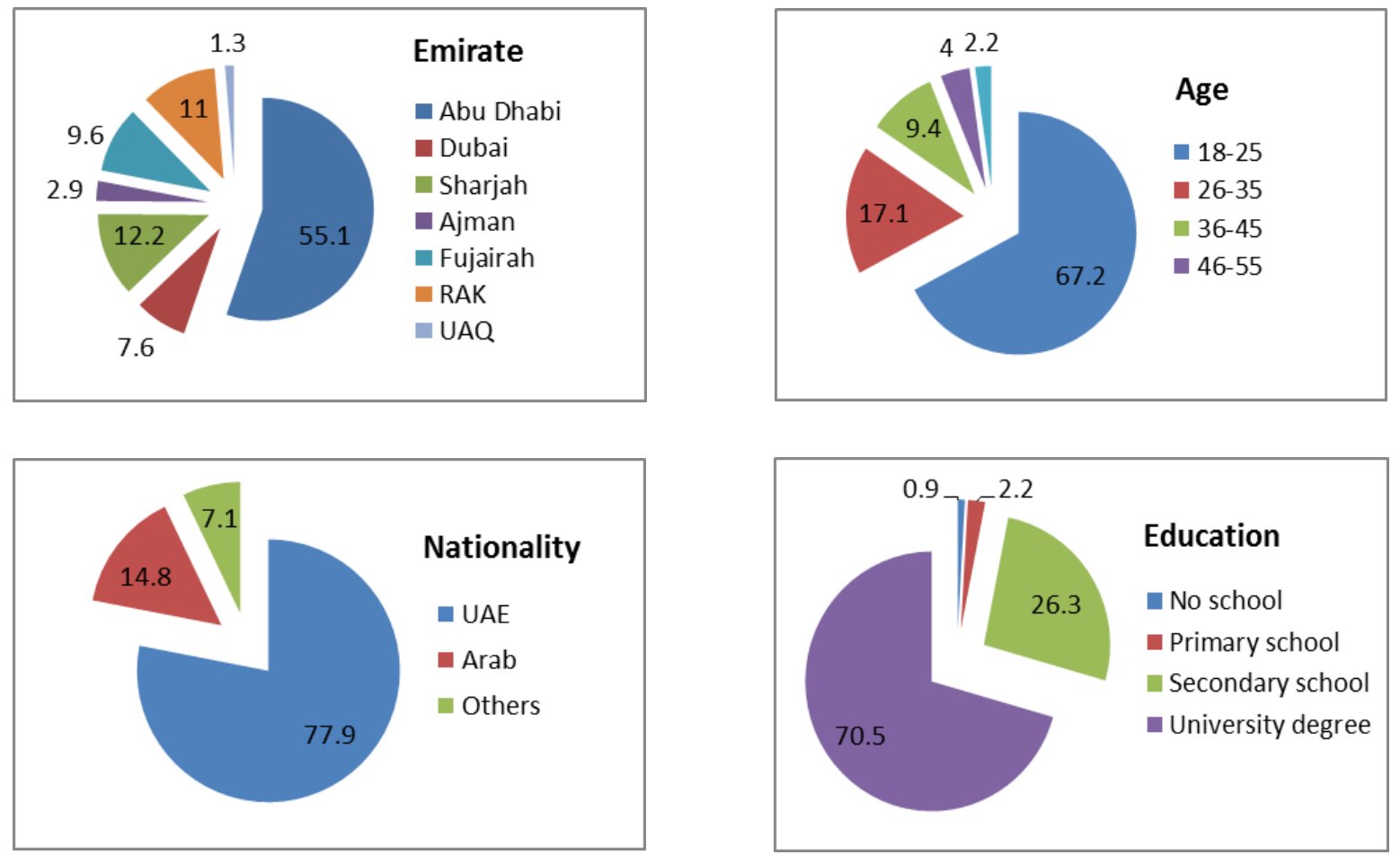

Figure 1. Demographical characteristics of the respondents

Results also revealed that respondents from all educational levels prefer drinking bottled water but those with a university degree constitute the highest percentage (55\%). In terms of association between drinking preferences and cost of bottled water, selectors of all three cost categories (cheap, reasonable, and expensive) prefer drinking bottled water but those who indicated that the cost of bottle water is reasonable constitute the highest percentage (46\%).

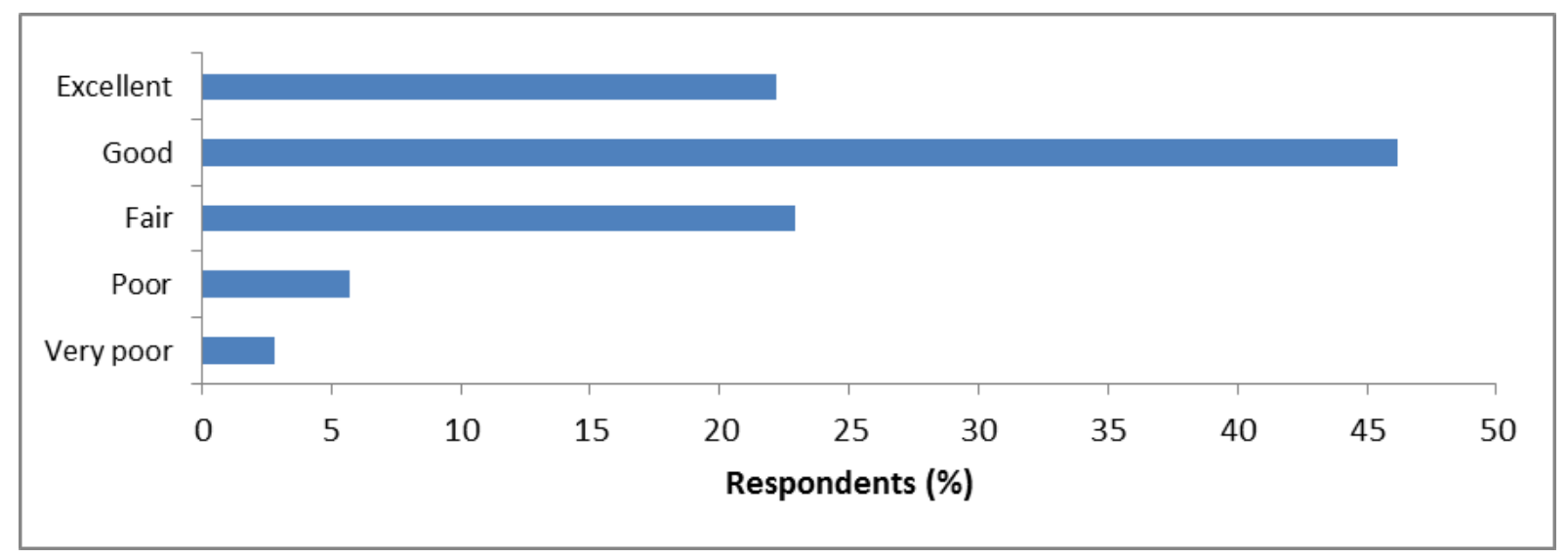

Figure 2. Quality of tap water in the UAE 
When asked about the main reasons for preferring to drink bottled water, taste was the most important reason, followed by concerns about tap water microbial contamination, concerns about tap water chemical pollution, social habit and then tap water chlorine smell (Fig. 3). These results are in agreement with those of Levallois et al. (1999) and Wait (2008), where respondents identified organoleptics (especially taste) as the main reason for drinking bottled water. On the other hand, the main concerns identified by the respondents in this study about bottled water were related to purity/cleanliness $(19 \%)$, cost $(15 \%)$, taste $(14.5 \%)$ and the origin of the water (12.5\%).

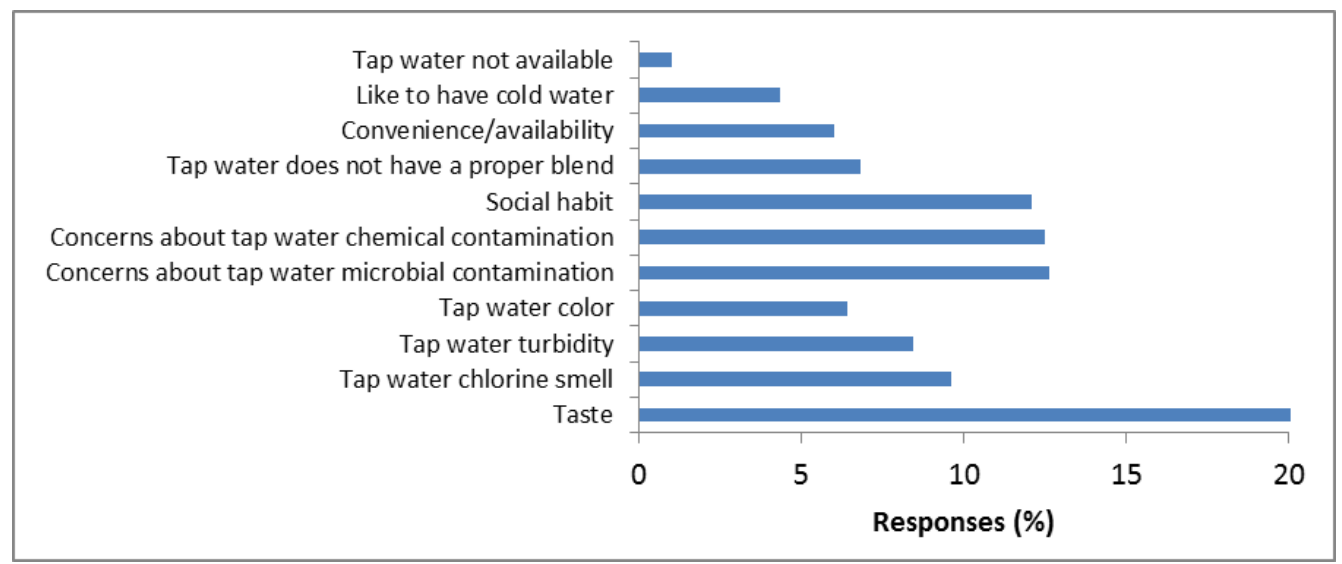

Figure 3. Reasons for drinking bottled water

When asked about the main concerns about tap water, $18 \%$ of the responses were related to sanitation of in-house water storage tanks. This is equivalent to $38 \%$ of the respondents expressing concern about this issue. Other issues include worry about building water pipes (15.9\%), treatment process (15\%), insufficient regulations $(14.6 \%)$, sanitation of the distribution system $(11.9 \%)$ and cleanliness of seawater $(11.5 \%)$ as shown in Fig. 4.

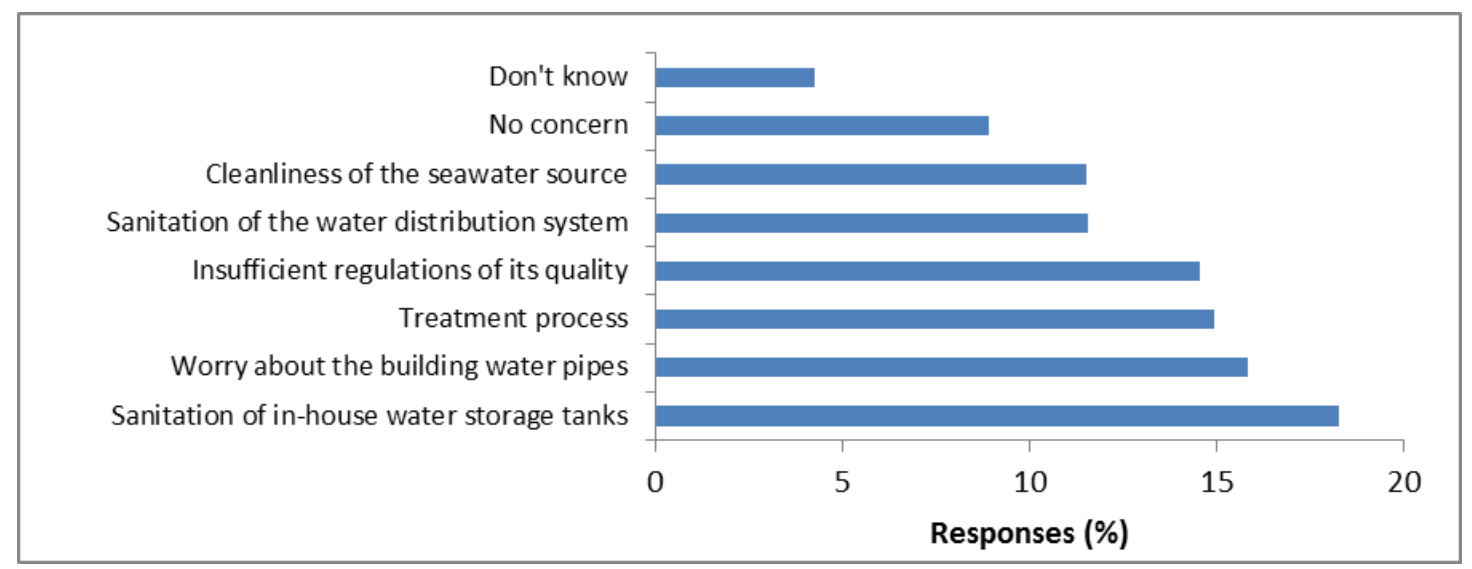

Figure 4. Concerns of drinking tap water

In-house storage tanks, building water pipes and the distribution network are usually referred to as contextual cues (Doria, 2010). Jones et al. (2007) found that some people attributed tap water contamination to the distribution network. Meanwhile, in the work of Contu et al. (2005) more than $50 \%$ of the survey participants indicated the conditions of the distribution network as one of the main causes of concern with their tap water. It should be noted that more than half of the respondents (54\%) in this study have a ground storage tank for 
municipal water at their residences, but $22 \%$ don't know how often the tank is cleaned. Also, $77 \%$ of the respondents have a roof water storage tank, but 32\% don't know how often the tank is cleaned. Example images of ground and roof water tanks are shown in Fig. 5 . The presence of these tanks in the UAE is necessary since water is not pumped continuously to residents.

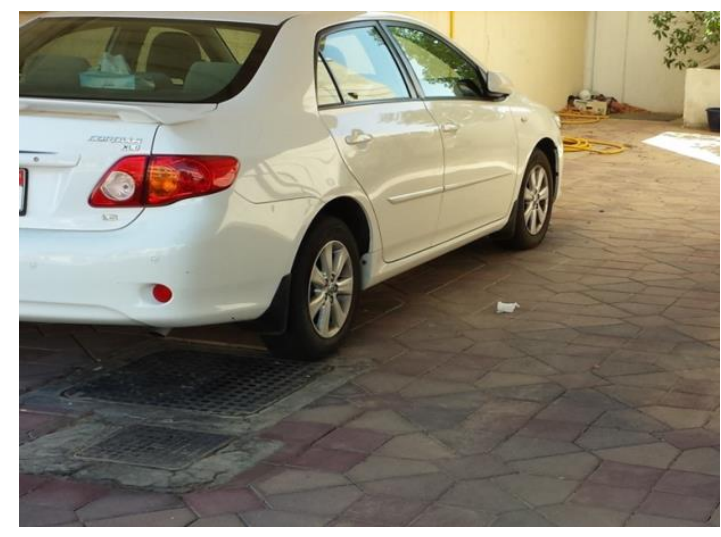

(a)

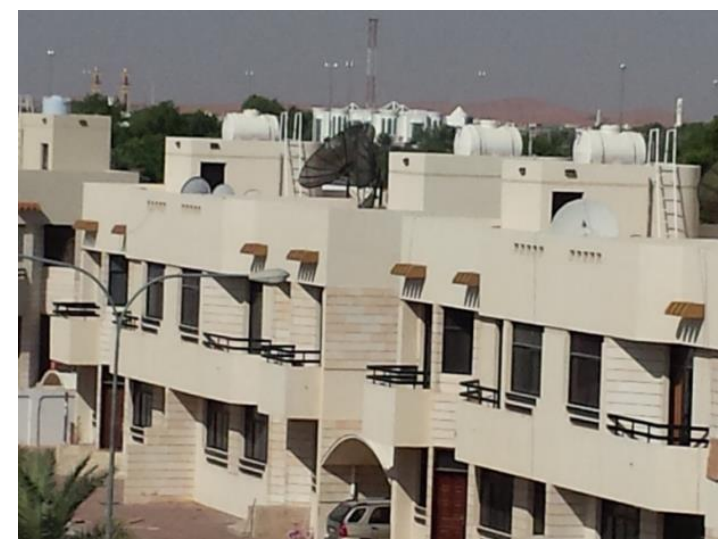

(c)

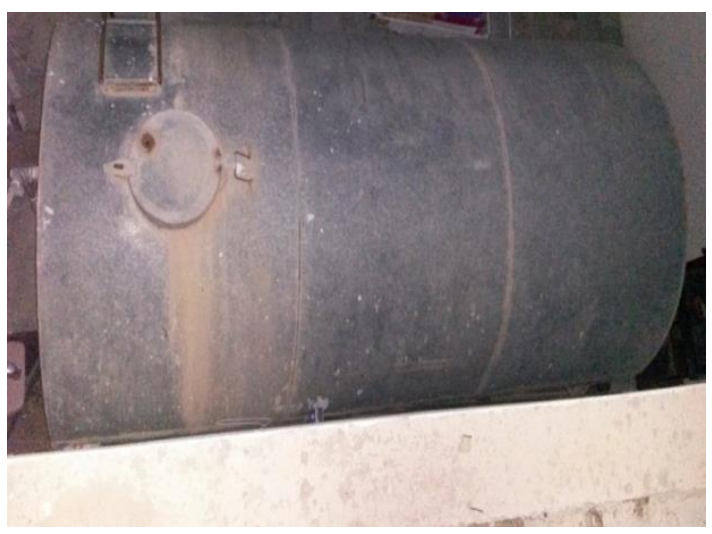

(b)

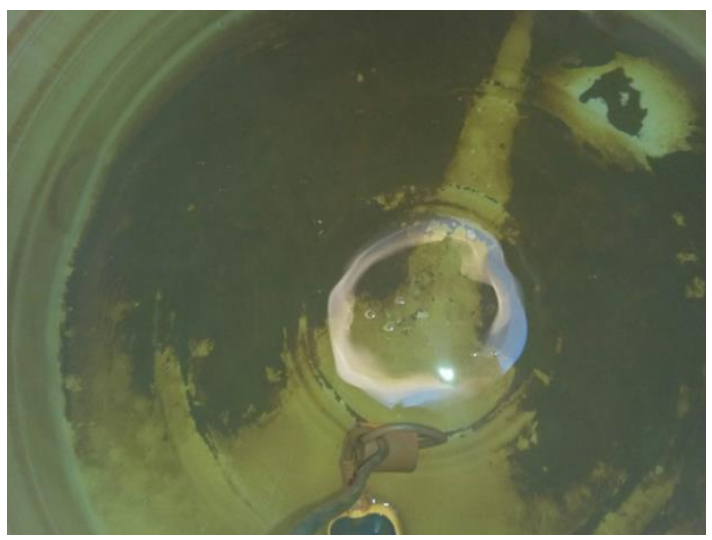

(d)

Figure 5. Images of water storage tanks; (a) a tank located under a parking area, (b) a tank located above ground, (c) tanks located on roofs, and (d) inside a water tank

Our results are consistent with previous findings which show that tap water odor, color and taste come first in the list of public concern (Ferrier, 2001). Following this comes health concerns and people's belief of tap water as being unsafe. According to Ferrier (2001), this belief is mainly due to previous bacterial contamination, seasonal shortage of tap water, fear of fecal contamination, toxic substances or high nitrate levels in agriculture areas and water running in old distribution pipelines. Wait (2008) identified that most UAE water users do not believe desalinated water, in general, is fit for regular drinking due to perceptions of mineral imbalances, concern about cleanliness of the seawater source, and sanitation of in-house water storage tanks. Amiri et al. (2013) sampled ground and roof water storage tanks of 11 houses located in the Emirate of Sharjah for a period of six weeks. Although none of the samples contained E. coli, they did contain other coliforms such as Klebsiella, Enterobacter spp., and Serratia. The authors found that about $73 \%$ of the collected samples showed a high total bacterial count (>10 CFU/100ml). They suggested cleaning the water 
tanks at least twice a year to prevent accumulation of contaminants. Further research, however, is needed to investigate if public concerns regarding tap water quality in the UAE are scientifically sound.

Pearson Chi-Square analysis was conducted to investigate possible association between drinking tap water and the perceived cost and drinking tap water and frequency of cleaning the in-house water tanks. The results revealed that respondents who indicated that bottled water is expensive tend to drink a combination of tap water and bottled water. Also, those who frequently drink tap water are more in the categories where the inhouse water tanks are cleaned regularly or they do not know how often the tanks are cleaned. However, no significant association was found between the cost of bottled water and the frequency of drinking tap water. Also, no significant association was found between cleaning the in-house water tanks and the type of water the respondents drink.

When asked about the actions that could be taken to encourage the public to drink tap water more, $18.6 \%$ of the responses were related to improving water treatment followed by provision of more information about tap water quality (18.5\%), inspection of water storage tanks (15.8\%), provision of free filters (12.9\%), and reducing/eliminating chlorine smell (11.9\%) as demonstrated in Fig. 6.

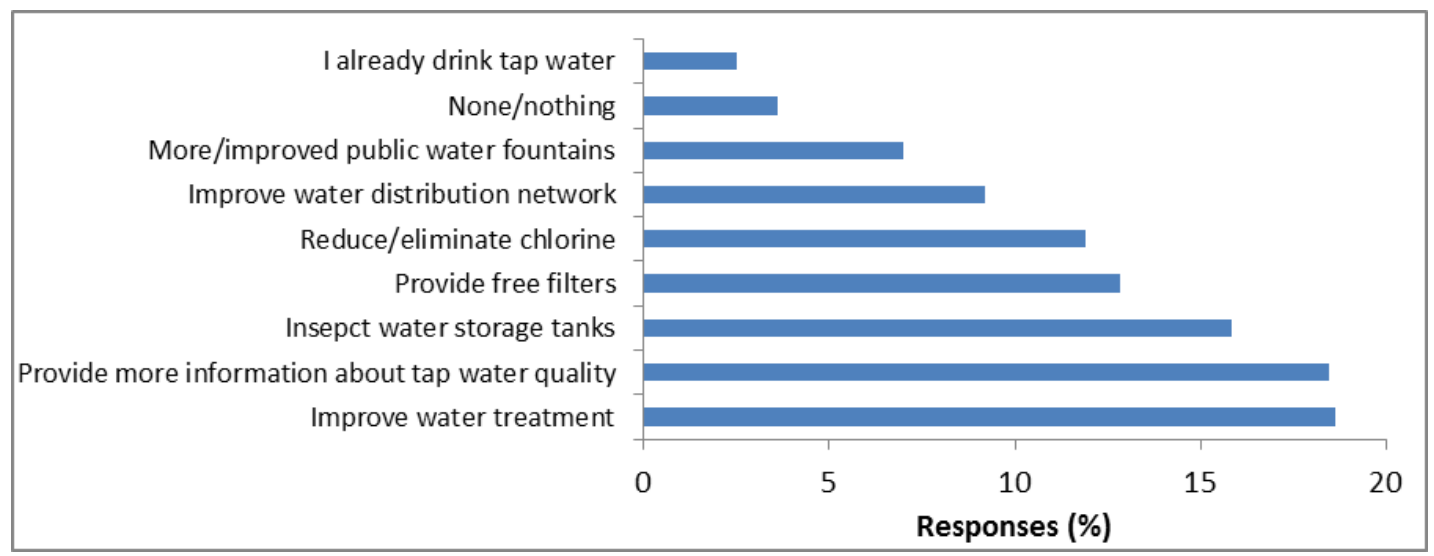

Figure 6. Actions to encourage people to drink more tap water more often

\section{Conclusion}

Many UAE residents drink bottled water, although a large fraction of them consider the quality of tap water as either good or excellent. The reasons for preference of bottled water in the country could be attributed in part to the high standard of living where the cost of bottled water is considered by the majority of the respondents as cheap or reasonable. Other influential factors include the belief that bottled water has a better taste and concerns about tap water contamination. The latter may stem from the perception that water is not sufficiently treated or contamination may be induced in tap water from the distribution system or the in-house storage tanks. More people in the UAE will be encouraged to drink tap water if the water utilities provide information about the quality of water and if regular inspection and cleaning of the in-house storage tanks is conducted.

\section{Acknowledgement}

The authors are thankful to the 2011-2014 students in the Water and Wastewater Technology classes at the UAE University who collected many of the survey forms. We also thank the anonymous reviewers for the exceptionally useful comments. 


\section{References}

Abrahams N., Hubbell B. and Jordan J. (2000), Joint production and averting expenditure measures of willingness to pay: do water expenditures really measure avoidance costs? Am. J. Agric. Econ., 82, 427-437.

Amiri A.H., Alkendi R.R. and Ahmed Y.T. (2013), Quantification of bacteria in domestic water storage tanks in Sharjah, Journal of Water Resources and Ocean Science, 2, 125-132.

Anadu E. and Harding A. (2000), Risk perception and bottled water use, J. AWWA, 92, 82-92.

Black R. (2009), Acqua minerale di Sangemini: the Italian mineral water industry finds a place at the table, J. Modern Italian Studies, 14, 184-198.

Botto S., Niccolucci V., Rugani B., Nicolardi V., Bastianoni S. and Gaggi C. (2011), Towards lower carbon footprint patterns of consumption: The case of drinking water in Italy, Environ. Sci. Policy, 14, 388-395.

Cidu R., Frau F. and Tore P. (2011), Drinking water quality: Comparing inorganic components in bottled water and Italian tap water, J. Food Compos. Anal., 24, 184-193.

Contu A., Carlini M., Maccioni A., Meloni P. and Schintu M. (2005), Evaluating citizens concern about the quality of their drinking water, Wat. Supply, 5, 17-22.

Dabeka R.W., Conacher H.B.S., Lawrence J.F., Newsome W.H., McKenzie A., Wagner H.P., Chadha R.K.H. and Pepper K. (2002), Survey of bottled drinking waters sold in Canada for chlorate, bromide, bromate, lead, cadmium and other trace elements, Food Additives \& Contaminants, 19, 721-732

Doria M.F. (2006), Bottled water versus tap water: understanding consumers' preferences, J. Wat. Health, 4, $271-276$.

Doria M.F. (2010), Factors influencing public perception of drinking water quality, Wat. Policy, 12, 1-19.

Dupont D., Adamowicz W.L. and Krupnick A. (2010), Differences in water consumption choices in Canada: The role of socio-demographics, experiences, and perceptions of health risks, J. Wat. Health, 8, 671-686.

Ferrier C. (2001), Bottled water: understanding a social phenomenon, AMBIO: A Journal of the Human Environment, 30, 118-119.

Finucane M., Alhakami A., Slovic P. and Johnson S. (2000), The affect heuristic in judgments of risks and benefits, J. Behav. Decision Making, 13, 1-17.

FWR (1996), Tap water consumption in England and Wales: Findings from the 1995 National Survey. Foundation for Water Research, Report No DWI0771.

Freire F., Thore S. and Ferrao P. (2001), Life cycle activity analysis: logistics and environmental policies for bottled water in Portugal. OR Spektrum, 23, 159-182.

Giacosa E. and Giovando G. (2012), Bottled water consumption: The case of Italy, World J. Soc. Sci., 2, 200 - 217.

Hu Z., Morton L.W. and Mahler R.L. (2011), Bottled water: United States consumers and their perceptions of water quality. Int. J. Environ. Res. Public. Health, 8, 565-578.

IBWA (2009), 2009 Market Report Findings, International Bottled Water Association, Available at: http://www.bottledwater.org/economics/ (accessed on 8.10.2014).

IBWA (2010), 2010 Market Report Findings, International Bottled Water Association, Available at: http://www.bottledwater.org/economics/ (accessed on 8.10.2014).

IBWA (2011), 2011 Market Report Findings, International Bottled Water Association, Available at: http://www.bottledwater.org/economics/ (accessed on 8.10.2014).

IBWA (2012), 2012 Market Report Findings, International Bottled Water Association, Available at: http://www.bottledwater.org/economics/ (accessed on 8.10.2014).

IBWA (2013), 2013 Market Report Findings, International Bottled Water Association, Available at: http://www.bottledwater.org/economics/ (accessed on 8.10.2014).

Jones A.Q., Dewey C.E., Dore K., Majowicz S.E., McEwen S.A., Waltner-Toews D., Henson S.J. and Mathews E. (2007), A qualitative exploration of the public perception of municipal drinking water, Wat. Policy, 9, 425-438. 
Levallois P., Grondin J. and Gingras S. (1999), Evaluation of consumer attitudes on taste and tap water alternatives in Quebec, Wat. Sci. Technol., 40, 135-139.

Mahajan R.K., Walia T.P., Lark B.S., Sumanjit (2006), Analysis of physical and chemical parameters of bottled drinking water, Int. J. Environ. Health Res, 16, 89-98.

Maraqa M.A. and Mohamed A.M.O. (2013), Key drivers for successful safety management system of construction activities in Abu Dhabi Emirate, Int. J. Advanced Fire, Explosive, Environment Safety and Disaster Management, 1, 1-17.

Nsanze H., Babarinde Z. and Al Kohaly H. (1999), Microbiological quality of bottled drinking water in the UAE and the effect of storage at different temperatures, Environ. Int., 25, 53-57.

Pintar K.D.M., Waltner-Toews D., Charron D., Pollari F., Fazil A., McEwen S.A., Nesbitt A. and Majowicz S. (2009), Water consumption habits of a south-western Ontario community. J. Wat. Health, 7, 276-292.

Roses R.P., Prassas E.S., and McShane W.R. (2004), Traffic Engineering, 3rd edition. Pearson Education Inc., New Jersey.

Saleem N. (2008), Beverage companies target UAE. The Gulf News, 13 February 2008, Available at: http://gulfnews.com/business/sectors/general/ (accessed on 12.3.2015)

Olson E.D. (1999), Bottled water: Pure drink or pure hype? National Resource Defense Council, New York, Available at: http://www.nrdc.org/water/drinking/bw/bwinx.asp (accessed on 12.9.2014).

UAE Year Book (2013), Available at: http://www.uaeyearbook.com (accessed on 15.4.2015).

Wait I. (2008), Changing perceptions: Water quality and demand in the United Arab Emirates, 13th IWRA World Water Congress, 1-4 September, Montpellier, France. 


\section{Appendix A: Survey form}

\section{Bottled versus Tap Water Quality in the UAE}

We would like to know your views about the quality of water you drink in the UAE.

Please note that this survey is solely intended for educational and research purposes.

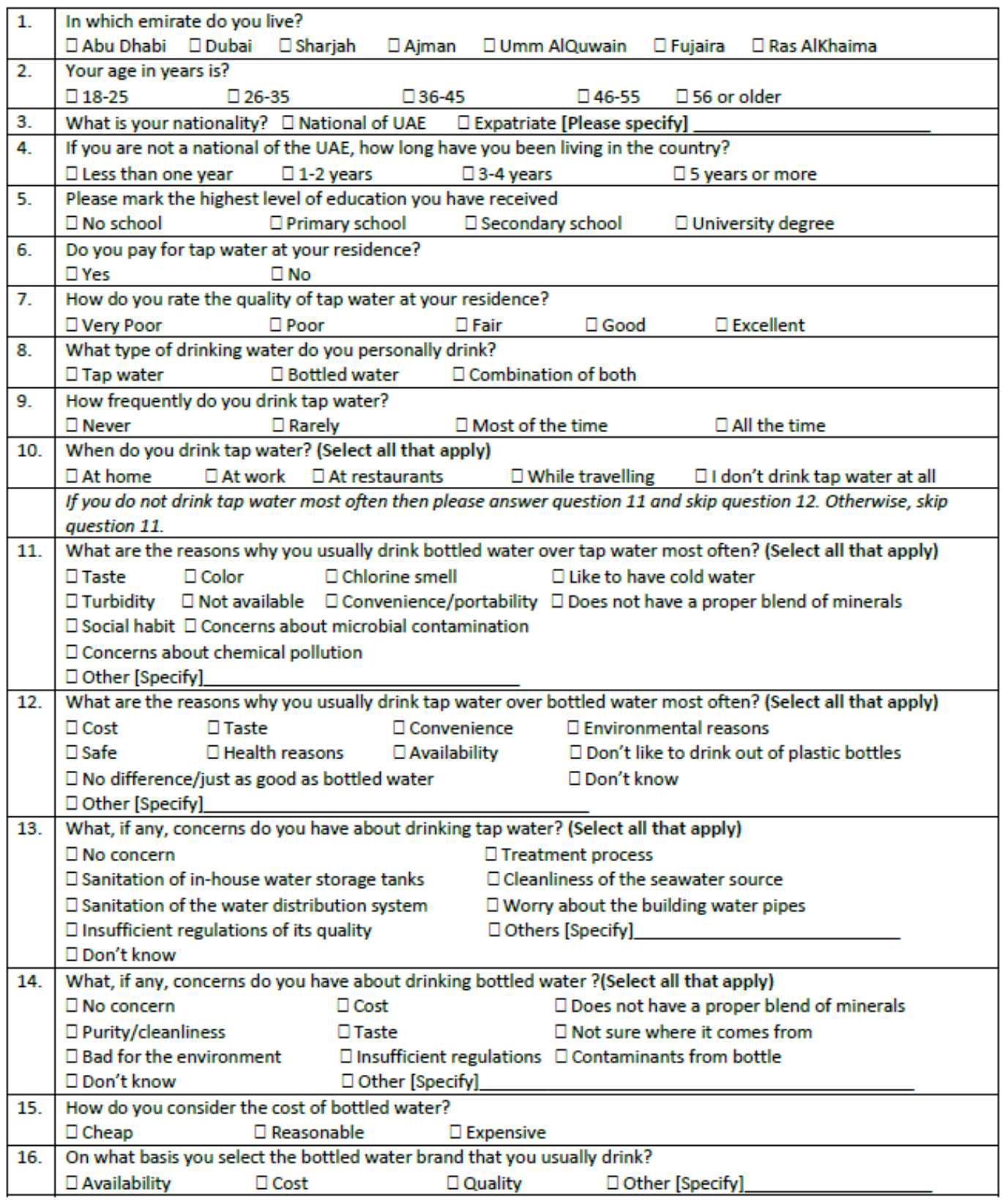




\section{UAEU}

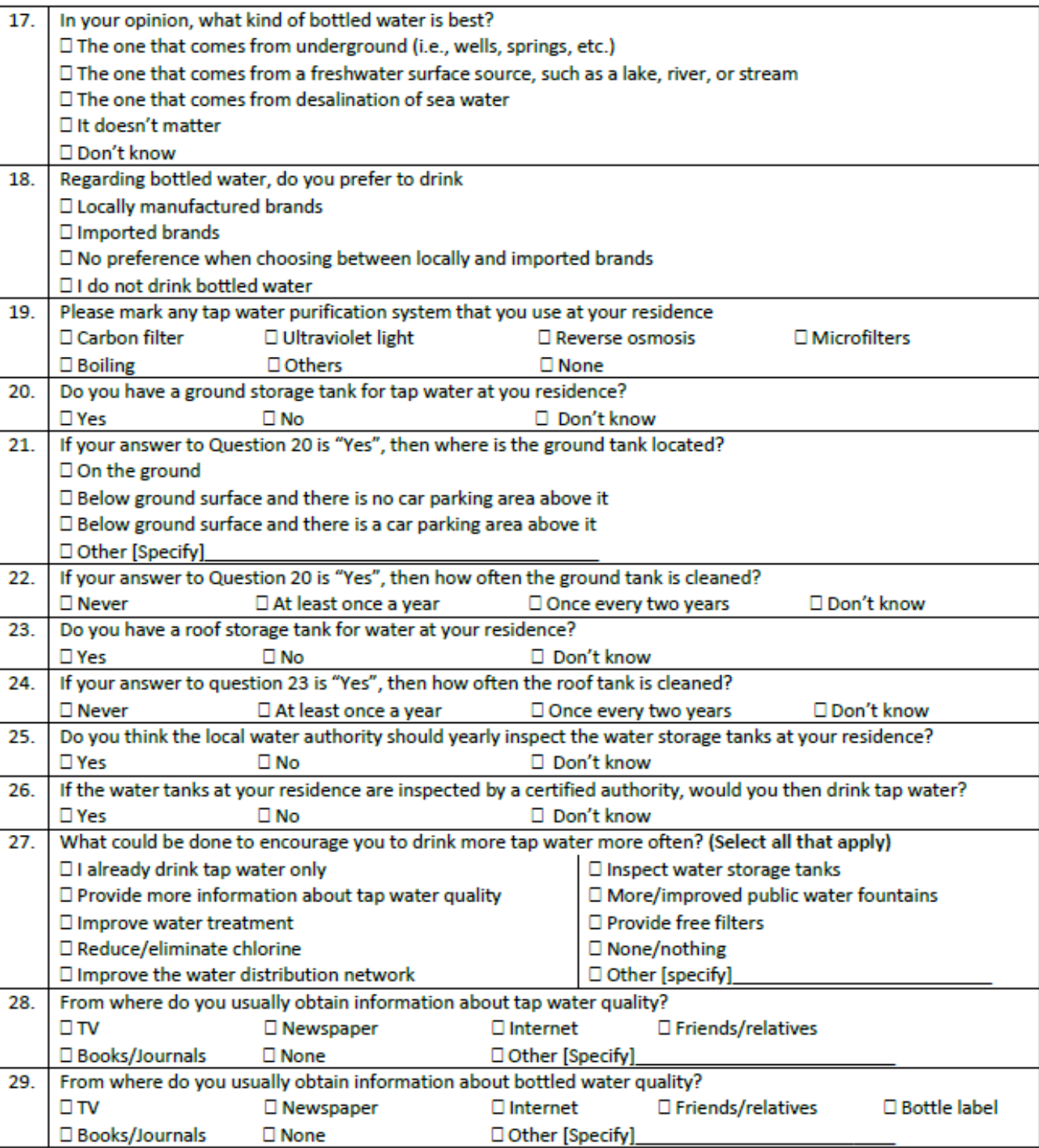

Thank you very much for your time and opinions. 